\title{
A ENFERMAGEM EM PORTUGAL NO SÉCULO XX: UM RETRATO HISTÓRICO
}

\author{
Helder Manuel GUERRA HENRIQUES \\ Instituto Politécnico de Portalegre - Escola Superior de Educação/ \\ CEISXX - Universidade de Coimbra/ C3I - IPP
}

Recibido: 30/07/2012

Aceptado: 03/10/2012

RESUMEN: El propósito de este trabajo es discutir la construcción profesional del grupo de enfermeros portugueses en el siglo XX. Vamos a argumentar que se trataba de un proceso influenciado por el Estado, otros grupos profesionales y un conjunto de conocimientos que, poco a poco, fueran apropiados por los enfermeros. Ancoramos, en termos teóricos, en Historia y Sociología de las profesiones. Desde el punto de vista metodológico, es un análisis socio-histórico, en una perspectiva diacrónica, que utiliza la legislación, bien como registros y fuentes orales como un corpus analítico de documentos.

PALABRAS CLAVE: Historia; Saberes; Estado; Enfermeros; Siglo XX.

ABSTRACT: This article's aim is to discuss the professional construction of the Portuguese nurses' group in the $20^{\text {th }}$ century. It is our belief that the process has been influenced by the government, by other professional groups and by a set of knowledge that has slowly been appropriated by nurses.

We root ourselves in History and in Sociology of Professions. From a methodological point of view, this paper is a socio-historical analysis in a diachronic perspective that uses legislation, archives and spoken testimonies as its documental corpus.

KEYWORDS: History; Knowledge; Government; Nurses; $20^{\text {th }}$ century.

\section{INTRODUÇÃO}

A compreensão sobre os processos de construção dos domínios profissionais constitui matéria relevante no contexto histórico. Em Portugal ainda são poucos os estudos que existem sobre a construção de processos de profissionalização ${ }^{1}$. O

${ }^{1}$ Cf. NóvoA, A. (1987). Le Temps des Professeurs - Analyse Socio-Historique de la Profession enseignante au Portugal (XVIIIe-XXe siécle). 2 Vols. Lisboa: Instituto Nacional de Investigação Cientifica; NóvoA, A. (1995). Profissão Professor. $2^{a}$ ed. Porto: Porto Editora; PITA, J. R. (1996). Farmácia, Medicina e Saúde Pública em Portugal (1772 - 1836). «Col. Minerva Historica». Coimbra: Minerva Editora; Rodrigues, M. L. (1999). Os Engenheiros em Portugal - 
propósito deste trabalho consiste precisamente em discutir e compreender o processo de construção histórica de uma atividade profissional: a enfermagem portuguesa. Esta atividade tem sido secundarizada pelos estudiosos, um pouco na linha daquilo que acontece com muitas das atividades que até á pouco tempo não eram consideradas "estabelecidas"2. No fundo, pretendemos responder às seguintes perguntas de partida:

Como se construiu a enfermagem em Portugal na centúria de novecentos? Quem influenciou este processo de construção? Que estratégias a enfermagem portuguesa e os seus atores encontraram para promover o grupo e o seu saber? Em suma, como se transformaram em atividade profissional?

Estas questões apresentam-se como linha discursiva do artigo. O estudo encontra-se ancorado, do ponto de vista teórico, à história ${ }^{3}$ e sociologia das profissões ${ }^{4}$. De facto, estes domínios científicos constituem para nós referências

Profissionalização e Protagonismo. Oeiras: Celta Editora; Silva, A. M. C. da C. e (2005). Formação e Construção de Identidades - Um estudo de caso centrado numa equipa multidisciplinar. Braga: Universidade do Minho; GonçALVES, C. (2006). Emergência e Consolidação dos Economistas em Portugal. Porto: Edições Afrontamento; Folgado, J. (2006). O lugar da ética e da auto-regulação na identidade profissional dos jornalistas. Braga: Universidade do Minho; TAVARES, D. (2007). Escola e Identidade Profissional - $O$ caso dos Técnicos de Cardiopneumologia. Lisboa: Edições Colibri/Instituto Politécnico de Lisboa.

${ }^{2}$ Etzioni, A. (1969). The Semi-professions and their organisation. New York: Free Press.

3 Cf. Henriques, H. M. G. (2012). Formação, Sociedade e Identidade Profissional dos Enfermeiros: A Escola de Enfermagem de Castelo Branco/Dr. Lopes Dias (1948 - 1988). Coimbra: Universidade de Coimbra; SiLva, H. R. (2010). Soigner à l'hôpital : histoire de la profession infirmière au Portugal (1886-1955). Paris/ Braga: Ecole de Hautes Études en Sciences Sociales /Universidade do Minho; Silva, A. I. (2008). A Arte de Enfermeiro: Escola de Enfermagem Dr. Ângelo da Fonseca, Coimbra: Imprensa da Universidade de Coimbra; AmENDOEIRA, J. (2006). Uma Biografia Partilhada da Enfermagem: A Segunda Metade do Século XX. Coimbra: Formasau; SoAReS, M. I. (1997). Da Blusa de Brim à Touca Branca - Contributo para a História do Ensino de Enfermagem em Portugal (1880-1950). Lisboa: Educa/Associação Portuguesa de Enfermeiros; Escobar, L. (2004). O Sexo das Profissões - Género e Identidade Socioprofissional em Enfermagem. «Col. Biblioteca das Ciências Sociais». Porto: Edições Afrontamento; Colliére, M - F. (1989). Promover a Vida - Da prática das Mulheres de Virtude aos Cuidados de Enfermagem. Lisboa: SEP; NUNES, L. R. M. (2003), Um Olhar Sobre o Ombro: Enfermagem em Portugal (1881- 1998), Loures: Lusociência.

${ }^{4}$ Cf. WitZ, A. (1992). Professions and Patriarchy. London/New York: Routledge; MACDONALD, K. (1999). The Sociology of the Professions. $2^{\circ}$ ed. London/Thousand Oaks/ New Delhi: Sage; LARSON, M. S. (1979). The Rise of Professionalism - a Sociological Analysis. Berkeley/Los Angeles/London: University Of California Press; Johnson, T. (1972). Professions and Power. Londres: Macmillan; FREIDSON, E. (1986). Professional Powers: A Study of the Institutionalization of Formal Knwoledge. Chicago/London: The University of Chicago Press; DubAR, C. e TrIPIER, P. (1998). Sociologie des Professions. Paris: Armand Colin; Delicado, A., Borges, V. e DiX, S. (Orgs.) 
teóricas capazes de promover a interpretação desejada sobre os processos de emergência e consolidação profissionais da enfermagem portuguesa.

Do ponto de vista documental, socorremo-nos de dois tipos de informação: 1) a legislação, que permite um enquadramento legal da atividade, que colocamos neste trabalho em evidência; 2) e, as fontes de arquivo, recolhidas principalmente numa instituição escolar de enfermagem (A Escola de Enfermagem de Castelo Branco/ Dr. Lopes Dias). Realçamos que, além das fontes identificadas, também recorremos a fontes orais e/ou iconográficas de modo a concretizar melhor as ideias que circulam no interior deste texto.

Quanto à abordagem metodológica, optamos pela análise sociohistórica, numa perspetiva diacrónica, dado que este método e suas respetivas técnicas de trabalho possibilitam a observação de diferentes cenários, a validação do discurso e das ideias e, também, permitem "colocar em crise" os diferentes testemunhos recolhidos, atribuindo-lhes validade científica.

Este artigo pode ser dividido em três partes, articuladas entre si, que caraterizam em termos genéricos, o processo de afirmação e consolidação da enfermagem em Portugal. A primeira fase inicia-se no último quartel do século XIX e decorre até ao fim da década de 30 do século passado. Este primeiro momento constitui o arranque do processo de emergência da atividade por via da institucionalização escolar e académica da enfermagem. Neste período surgiram as primeiras instituições escolares que influenciaram o processo de construção identitária da enfermagem portuguesa. Destaca-se a Escola de Enfermagem privada fundada por Augusto Costa Simões, em Coimbra, em 1881, e a primeira Escola oficial de Enfermagem criada em Lisboa, em 1901, surgindo a partir desta data um conjunto de outras instituições escolares, sobretudo, já na década de 30, da centúria passada, de índole religiosa.

A segunda fase, assume como balizas temporais as décadas de 40 e 70 do século $\mathrm{XX}$. Esta época ficou marcada por dois elementos que influenciaram decisivamente a definição identitária da enfermagem em Portugal. Por um lado, a importância que o Estado atribuiu às questões da assistência e à necessidade de formar enfermeiros credenciados; e, por outro lado, a preferência por elementos do género feminino

(2010). Profissão e Vocação - Ensaios sobre grupos profissionais. Lisboa: Instituto de Ciências Sociais; Abreu, W. C. de (2001). Identidade, Formação e Trabalho - Das Culturas Locais às Estratégias Identitárias dos Enfermeiros. Coimbra/Lisboa: Formasau/Educa; АввотT, P. e Meerabeau, L. (1998). The Sociology of the caring professions. $2^{\mathrm{a}}$ ed. London/New York: Routledge; Аввотт, A. (1988). The System of Professions - an Essay on the Division of Expert Labor. Chicago/London: The University of Chicago Press. 
capazes de representar um conjunto de valores relacionados com o "cuidar" que o Estado queria transmitir naquela época para a sociedade.

A terceira fase decorre até à década de 90 da centúria passada. Este arco temporal representa o início do processo de consolidação de uma nova visão para a enfermagem portuguesa. Uma atividade que se pretendia profissional e que para atingir esse estatuto socorreu-se de um conjunto de saberes que ajudaram o grupo dos enfermeiros a consolidar um domínio profissional relacional e que, em certa medida, permitiu a integração da enfermagem no ensino superior português e posteriormente a constituição da ordem e do estatuto profissional.

Vejamos, em particular, cada uma destas fases e as caraterísticas gerais das mesmas na tentativa de responder às questões-chave identificadas previamente, depois de uma breve abordagem teórica sobre este assunto. Este artigo resulta de uma investigação doutoral realizada na Faculdade de Psicologia e de Ciências da Educação da Universidade de Coimbra, entre os anos de 2008 e 2012.

\section{ESTADO, FORMAÇÃO E IDEOLOGIA PROFISSIONAL: CONSTRUIN- DO NEXOS}

Ao longo dos anos de investigação sobre a temática das profissões percebemos que não podemos compreender o modo como se constroem as atividade profissionais, ou como se produzem as identidades coletivas associadas a uma determinada ideologia profissional, sem percebermos primeiro o importante papel que os processos formativos assumem neste contexto e, por outro lado, os fatores externos e internos que influenciam os processos de emergência de uma atividade profissional.

Em sentido oposto aos princípios defendidos pela perspetiva funcionalista da sociologia das profissões, verificamos que a aquisição do estatuto de profissão pelas atividades ocupacionais resulta não de um modelo padrão, mas de um conjunto de variáveis cuja análise permite compreender o processo de emergência e consolidação de uma jurisdição profissional ${ }^{5}$. A interpretação sobre os processos de afirmação das ocupações, e a sua transformação em profissões só é possível quando:

“(...) apreendemos o caminho percorrido pelos grupos, as singularidades, as estratégias e as trajetórias que foram desenvolvidas na tentativa de alcançar o referido estatuto de "profissional" ou "especialista" e daí retirar os benefícios individuais e coletivos. Neste sentido, a questão não se deve

${ }^{5}$ Аввотт, А. (1988), The System of Professions ... cit. pp. 59 e seguintes. 
centralizar na existência de um modelo ideal aplicável a todos os grupos que pretendem afirmar-se profissionalmente, mas observar o desenvolvimento dos diferentes grupos, numa perspetiva processual e sistémica" ${ }^{\text {, }}$.

De acordo com a dinâmica interpretativa proposta na citação anterior, consideramos que as profissões são elementos instáveis e complexos e por isso devem ser estudadas na sua vertente histórica, social e política de forma a compreender o papel das atividades no interior da sociedade e em articulação com outros grupos "de fronteira" e o próprio Estado. Como já percebemos, não é tarefa simples encontrar uma definição padrão para o conceito de profissão. Neste sentido, torna-se relevante a necessidade da análise histórica uma vez que permite, através de metodologias próprias, compreender o conceito de profissão a partir de múltiplas leituras, análises e perspetivas que podem ser realizadas dependendo de fatores internos dos grupos, mas também de variáveis externas que influenciam a construção profissional de qualquer atividade. Por isso, consideramos que:

"Uma profissão surge como resultado das lutas, reivindicações, estratégias seguidas por um determinado grupo ocupacional na tentativa de alcançar maior credibilidade social, académica e estatal, num determinado período temporal. Do mesmo modo, um grupo ocupacional alcança maior prestigio se tiver uma formação especializada e um lugar propício à sua socialização profissional. É aqui que as escolas assumem, por norma, um papel preponderante no processo de acreditação e socialização dos indivíduos que pretendem integrar um determinado grupo"7.

Neste sentido, propomos uma breve discussão centrada em três níveis de análise articulados umbilicalmente entre si: o papel das instituições escolares no processo de emergência e consolidação das atividades profissionais; a ação do Estado na construção de jurisdições profissionais ${ }^{8}$; e a importância das questões de género na definição de uma identidade profissional da enfermagem em Portugal.

As escolas apresentam-se como elementos relevantes e participantes no processo de afirmação dos grupos profissionais. A ideia de que para poder integrar um grupo profissional é necessário ao candidato possuir um conjunto de requisitos,

${ }^{6} C f$. Ferreira, A. G. \& HenriQues, H. M. G. (2012). 174As normas e os valores na construção da identidade profissional da enfermagem portuguesa - décadas de 40 a 80 (séc. XX)». Estudos do Século XX. 12, pp. 143 e 144 (no prelo).

${ }^{7}$ Ferreira, A. G. \& Henriques, H. M. G. (2012). «As normas e os valores na construção da identidade profissional da enfermagem portuguesa (...)»... cit., pp.144.

${ }^{8}$ Аввотт, А. (1988). The System of Professions... cit., pp. 40 e seguintes. 
encontra objetivamente nas escolas esse papel seletivo e credencialista ${ }^{9}$. Isto é, qualquer individuo que pretenda integrar um grupo e exercer uma atividade profissional legalmente, é sujeito a processos de recrutamento complexos, a dinâmicas formativas rigorosas e, consequentemente, obrigado a cursar numa escola habilitadora para o exercício da atividade profissional.

Neste sentido, embora não seja esse o objetivo central deste trabalho, é relevante compreendermos os dispositivos de recrutamento dos candidatos, a forma que as escolas utilizam para proceder à sua seleção e também o modo como, no interior da formação, se procede à socialização dos indivíduos, motivando-os para a aquisição de valores promotores de uma consciência de grupo e, indubitavelmente, de um domínio profissional próprio ${ }^{10}$. Ora, as escolas assumem um papel da maior importância desde o momento da seleção dos candidatos, passando pelo período formativo até á aquisição de um diploma que, em regra, é reconhecido por outros grupos profissionais, pela Sociedade e pelo Estado.

A par da formação e do papel reconhecido das instituições escolares emerge a ação política, como elemento variável e influenciador da construção de jurisdições e identidades profissionais. Na verdade, o Estado é um elemento que se encontra articulado com as Escolas e que influencia decisivamente, por exemplo, os processos de recrutamento e a seleção dos indivíduos.

O caso das profissões de saúde e em concreto da enfermagem é paradigmático. $\mathrm{O}$ Estado ao longo de várias décadas $(40-60$ do século $\mathrm{XX})$ interveio no sentido de promover a enfermagem como uma atividade feminina ${ }^{11}$. Se numa primeira fase (finais do século XIX - década de 30 do séc. XX) não surgem indicações legais explícitas sobre o recrutamento preferencial de elementos do género feminino, com a intervenção do Estado na década de 40 (séc. XX), e de acordo com o papel que o regime político do Estado Novo atribuía à mulher, surgiram um conjunto de discursos legais que incentivavam as escolas de enfermagem a recrutar elementos do género feminino dado que estas representariam um conjunto de preceitos morais que o regime político da época procurava evidenciar. O Estado, em articulação com as escolas de enfermagem, recrutavam essencialmente mulheres, proibindo o seu casamento, e tornando a enfermagem um prolongamento da esfera privada para o

${ }^{9}$ Freidson, E. (1986). Professional Powers... cit., pp. 63 e seguintes.

10 Henriques, H. M. G. (2012). Formação, Sociedade e Identidade Profissional dos Enfermeiros... cit., pp. 375 e seguintes.

11 Carvalho, T. et al. (2010). Profissão e Vocação - Ensaios sobre grupos profissionais. Lisboa: ICS, pp ., 23 e seguintes. 
domínio público. Constituía-se, deste modo, uma espiral hierárquica de obediência onde o Estado promovia a enfermagem como um "verdadeiro" sacerdócio. Isto faz do Estado, numa lógica credencialista e articulada com as escolas, um elemento ativo no processo de emergência e consolidação de uma jurisdição profissional da enfermagem portuguesa. O Estado estabelece desde há muito tempo conexões com as profissões, umas vezes atribuindo-lhes papéis relevantes no interior da Sociedade, outras vezes retirando-lhes privilégios direta ou indiretamente. Por tudo isto, consideramos que o Estado, na relação com as instituições escolares, promove a divisão social e a segregação sexual do trabalho ${ }^{12}$ e apresenta-se como um elemento dinâmico na construção socioprofissional das mais diferentes áreas de intervenção do seu interesse. Algumas das atividades ocupacionais alcançaram um estatuto de profissão, exatamente porque o Estado necessitava de mão-de-obra mais qualificada para lidar com problemas sociais que podiam colocar em causa a sua própria existência. A enfermagem constitui o exemplo do que acabamos de referir. O Estado foi um importante elemento de intervenção na construção profissional da enfermagem portuguesa, umas vezes valorizando o grupo, outras vezes recuando e criando estratégias que não ajudaram ao desenvolvimento profissional do mesmo.

Vejamos, agora, um pouco da história da enfermagem portuguesa na sequência desta discussão teórica que apresentamos, tomando sempre em linha de conta as questões orientadoras deste trabalho que procuramos objetivar entre a teoria e o universo "empírico".

\section{A ENFERMAGEM PORTUGUESA: ÚLTIMO QUARTEL DO SÉCULO XIX - DÉCADA DE 40 DO SÉCULO XX}

Desde o século XIX que o Estado mostrou interesse pelas questões relacionadas com a assistência pública. No liberalismo, em 1836, Passos Manuel reformou as Escolas de Cirurgia de Lisboa e do Porto transformando-as em "Escolas Médicocirúrgicas" $"$. Esta reorganização indiciava ligações àquilo que poderia vir a fazer parte do domínio dos enfermeiros quando se referia à existência de um curso de parteiras ${ }^{14}$. No documento pode ler-se que "haverá em cada uma das Escolas

12 Durkheim, É. (1984). A Divisão do Trabalho Social. Lisboa: Editorial Presença.

${ }^{13}$ Diário do Governo (D.G). nº 293, de 10 de Dezembro de 1836.

14 Henriques, H.M.G. (2012). Formação, Sociedade e Identidade Profissional dos Enfermeiros... cit., pp.146 e seguintes. 
Médico-cirúrgicas um curso biennal, e gratuito, theórico, e prático, destinado especialmente para a instrucção de Parteiras"15.

A necessidade de institucionalizar a formação de enfermeiros em Portugal foi crescendo ao longo da segunda metade da centúria de oitocentos. No último quartel do século XIX surgiram as primeiras experiências institucionais relacionadas com a formação de enfermeiros. Em regra, e não desconsiderando experiências pontuais anteriores, assume-se que a primeira escola particular de formação de enfermeiros surgiu em 1881, na cidade de Coimbra, fundada pelo médico António Augusto da Costa Simões, administrador dos Hospitais da Universidade de Coimbra ${ }^{16}$. Esta escola tinha como objetivo oferecer uma formação adequada aos enfermeiros e enfermeiras e "habilitar as criadas do estabelecimento a poderem concorrer às vagas, que se estavam dando, no quadro das enfermeiras, à falta de pessoal habilitado na localidade com as simples noções de instrução primária"17. Todavia, as circunstâncias da fundação da escola de enfermagem e o declínio do estado de saúde do fundador não possibilitaram a continuidade desta primeira experiência de formação de enfermeiros portugueses. Durante essa mesma década de 80, ainda surgiram mais algumas experiências, em Lisboa e no Porto ${ }^{18}$, todavia sem grandes resultados.

Os alvores do novo século trouxeram novas esperanças para a formação de enfermeiros e para a afirmação de uma atividade que mais não era do que executora de tarefas sem qualquer tipo de reconhecimento académico, social ou profissional. Em 1901, surgiu a primeira escola oficial de enfermagem portuguesa: A Escola Profissional de Enfermeiros do Hospital Real de S. José. Os Estatutos desta escola foram aprovados pelo Decreto-Lei de 10 de Setembro e assinados por Ernesto Rodolpho Hintze Ribeiro. Neste texto encontramos os objetivos que levaram à fundação da instituição que pretendia sobretudo:

“(...) dar aos indivíduos que se destinem à profissão de enfermeiros a instrucção doutrinária e os conhecimentos de pratica, que as exigências da sciencia actual reclamam em quem tenha de cumprir prescripções medicas ou cirúrgicas e de prestar cuidados de enfermagem a doentes" ${ }^{19}$.

${ }^{15}$ D.G. no 293 , de 10 de Dezembro de 1836, pp. 13.

${ }^{16}$ SoAres, M. I. (1997). Da Blusa de Brim à Touca Branca... cit., pp. 25 e seguintes.

${ }^{17}$ SoARes, M. I. (1997). Da Blusa de Brim à Touca Branca... cit., pp. 32.

18 Cf. Silva, H. R. (2010). Soigner à l'hôpital : histoire de la profession infirmière au Portugal (1886-1955). Paris/ Braga: Ecole de Hautes Études en Sciences Sociales /Universidade do Minho.

${ }^{19}$ Art. $1^{\circ}$ dos Estatutos da Escola Profissional de Enfermeiros do Hospital Real de S. José, Diário do Governo ${ }^{\circ} 204$ de 12 de Setembro de 1901 (data da publicação do documento). 
Iniciava-se, deste modo, um processo de construção de um domínio profissional: o da enfermagem. Formalmente, o Estado considerava a necessidade de formar enfermeiros qualificados para exercerem a sua atividade em contexto hospitalar, muito embora sob a dependência das respetivas administrações dos hospitais que eram controlados pelos médicos. A enfermagem encontrava aqui um entrave ao processo de desenvolvimento profissional da sua atividade. A dependência face aos hospitais e aos seus administradores, médicos. Observamos esta caraterística ao longo de quase toda a primeira metade do século XX. A consolidação do grupo dos enfermeiros estava assim colocada em causa pelo domínio médico em articulação com o Estado.

A aproximação aos anos 20 , do século passado, constituiu uma nova etapa de reestruturação dos Hospitais da cidade de Lisboa transformando-os em Hospitais Civis, onde se integrava também a Escola Profissional de Enfermeiros, criada no início do século XX (1901). Esta instituição foi reformulada e, inclusivamente, a sua designação foi alterada para Escola Profissional de Enfermagem (1918). A escola estava destinada, principalmente, à habilitação de pessoal para os Hospitais Civis de Lisboa. A instituição reabriu, em 1919, sob a direção de Costa Sacadura, médico, defendendo a enfermagem como auxiliar da medicina, dando continuidade à ideia de enfermagem como uma ocupação subalterna e dependente do saber médico. Nesta escola funcionaram o curso geral e complementar de enfermagem ${ }^{20}$ onde já se exigia alguns requisitos habilitacionais para integrar a mesma.

Gradualmente, a enfermagem foi procurando ganhar credibilidade através de processos formativos. $\mathrm{O}$ surgimento de outras instituições escolares, principalmente a partir de meados da década de 20, do século passado, constitui prova disso mesmo. Ao longo da década de 30 , devido a um conjunto de transformações essencialmente políticas, e consequentemente sociais, circularam novos princípios na sociedade portuguesa, influenciados pelo Estado. Esta década ficou associada à institucionalização de um novo regime político em Portugal: o Estado Novo. Em 1933 foi aprovada uma nova constituição que implementava formalmente o Estado Novo. Este regime político caraterizava-se por ser autoritário, corporativista, antiparlamentar, antipartidário e ideologicamente com aproximações aos princípios da moralidade católica. O seu principal líder foi o

${ }^{20}$ De acordo com Lucília Nunes, o regulamento desta escola foi aprovado anos mais tarde, em 1922 (Decreto $\mathrm{n}^{\circ}$ 8:505 de 25 de Novembro). O curso geral tinha a duração de dois anos, era exigida a certidão de instrução primária do $2^{\circ}$ grau para aceder ao mesmo e habilitava para o quadro de enfermagem dos hospitais, exceto os lugares de chefia. 
professor doutor António de Oliveira Salazar ${ }^{21}$. O novo regime político caraterizase por novos princípios e valores que passaram a caraterizar a sociedade portuguesa durante mais de 40 anos apostando, por exemplo, numa educação nacionalista. Por outro lado, o papel da mulher encontrava-se bem definido. Para Oliveira Salazar, a mulher portuguesa caraterizava-se e dividia-se do seguinte modo:

"Temos que distinguir. A mulher solteira que vive sem família, ou tendo de sustentar a família, acho que devem ser dadas todas as facilidades legais para prover o seu sustento e ao sustento dos seus. Mas a mulher casada, como o homem casado, é uma coluna da família, base indispensável duma obra de reconstrução moral. Dentro do lar, claro está, a mulher não é uma escrava. Deve ser acarinhada, amada e respeitada, porque a sua função de mãe, de educadora dos seus filhos, não é inferior à do homem. (...) Deixemos, portanto, o homem a lutar com a vida no exterior, na rua...E a mulher a defendê-la, a trazê-la nos seus braços no interior da casa. Não sei afinal qual dos dois terá o papel mais belo, mais alto e mais útil (..., ${ }^{, 22}$.

No domínio dos cuidados sociais e de saúde o Estado Novo associou a figura da mulher à prática da assistência, personalizando desse modo as escolas de enfermagem e, consequentemente, a atividade profissional, maioritariamente, ao género feminino. A mulher passou a encontrar-se no centro das atividades formativas das escolas de enfermagem e no cruzamento com uma moral profissional de matriz católica que se pretendia implementar na enfermagem ${ }^{23}$. A enfermagem passou a ser apresentada como uma atividade feminina, como referimos anteriormente, com características religiosas, conventuais e morais na sequência da ideologia defendida e promovida por Oliveira Salazar.

Podemos considerar que esta primeira fase do processo de consolidação da enfermagem portuguesa foi marcada pela institucionalização da formação de enfermeiros em Portugal, mas também pela dependência da enfermagem face às administrações hospitalares, dificultando o processo de reconhecimento profissional da atividade. Todavia, a partir da década de $30 \mathrm{com}$ um novo regime político faz-se notar já a presença do Estado na construção do domínio profissional, em articulação com um grupo profissional "estabelecido" que eram os médicos, atribuindo à mulher funções específicas no seio da sociedade portuguesa de então.

${ }^{21}$ Após o afastamento, por doença, de António de Oliveira Salazar da presidência do conselho de ministros (1932 - 1968), assumiu esse cargo o professor doutor Marcelo Caetano (1968 - 1974).

${ }^{22}$ Entrevista de António Ferro a António de Oliveira Salazar, 1933, pp. 156 e 157.

23 Henriques, H. M. G. (2012). Formação, Sociedade e Identidade Profissional dos Enfermeiros... cit., pp. 169 e seguintes; EscobAR, L. (2004). O Sexo das Profissões... cit., pp. 20 e seguintes. 
$\mathrm{Na}$ verdade, o Estado nesta primeira fase responde às necessidades hospitalares promovendo a formação adequada de executores de tarefas e de auxiliares dos médicos. Algo que prosseguirá, até certa altura, na segunda metade da centúria de novecentos.

\section{A ENFERMAGEM PORTUGUESA NO ESTADO NOVO (1942 A 1965)}

A década de 40 do século XX trouxe mudanças no entendimento do Estado em relação à importância da enfermagem. O Estado considerava que a enfermagem podia ser uma atividade exemplar e vigilante no interior da sociedade portuguesa. Entre a década de 40 e os anos 60, o regime político da época construiu uma ideia de enfermeira que devia possuir um conjunto de requisitos para ingressar nas escolas de enfermagem e consequentemente no grupo. Por outro lado, o Estado promoveu um conjunto de intervenções que visavam combater a falta de recursos humanos na área da saúde. Apesar da intervenção do Estado que aparentava valorizar a enfermagem e a construção de uma jurisdição profissional própria, isso não se verificou uma vez que a política estatal era de contínuos avanços e recuos. Os enfermeiros durante este período nunca alcançaram a desejada autonomia e, pelo contrário, encontraram-se numa situação de submissão ao Estado e a outros grupos profissionais.

Entre 1942 e 1965 a enfermagem portuguesa era procurada por poucos indivíduos. Era uma ocupação pesada, exigente e com um desenvolvimento profissional comprometido e submisso ao Estado e aos Médicos. Embora a intervenção do Estado no domínio da enfermagem, em 1942, tenha constituído um importante passo na sua valorização enquanto atividade que procurava afirmar-se $\mathrm{e}^{24}$; na mesma década, em 1947, o Estado criou dispositivos que impediram e/ou dificultaram o processo de afirmação profissional dos enfermeiros portugueses ${ }^{25}$. Desde logo, deve salientar-se que no final da década de 40 criou dois níveis de "enfermeiros": os auxiliares de enfermagem e os enfermeiros gerais. Os primeiros, meros executores de tarefas, com uma formação de pouco mais de 1 ano e com uma instrução ao nível do ensino primário; os segundos com uma formação, a partir de $1952^{26}$, de 3 anos, com exigências literárias de ingresso superiores, embora baixas, assumindo como função coadjuvar diretamente o médico, prolongando-se a ideia, que já referimos anteriormente, da enfermagem como auxiliar da medicina. A existência de auxiliares e enfermeiras não favoreceu o

\footnotetext{
${ }^{24}$ Decreto-Lei n ${ }^{\circ}$ 31.913, de 12 de Março de 1942.

${ }^{25}$ Decreto-Lei no 36.219 , de 10 de Abril de 1947.

${ }^{26}$ Decreto-Lei $n^{\circ} 38.885$, de 28 de Agosto de 1952.
} 
reconhecimento socioprofissional da enfermagem, pelo contrário, acabou, mais tarde, por trazer enormes problemas e divisões para o interior do grupo.

Ilustração 1 - O diretor da Escola de Enfermagem de Castelo Branco, José Lopes Dias, e as enfermeiras (Anos 60) $)^{27}$

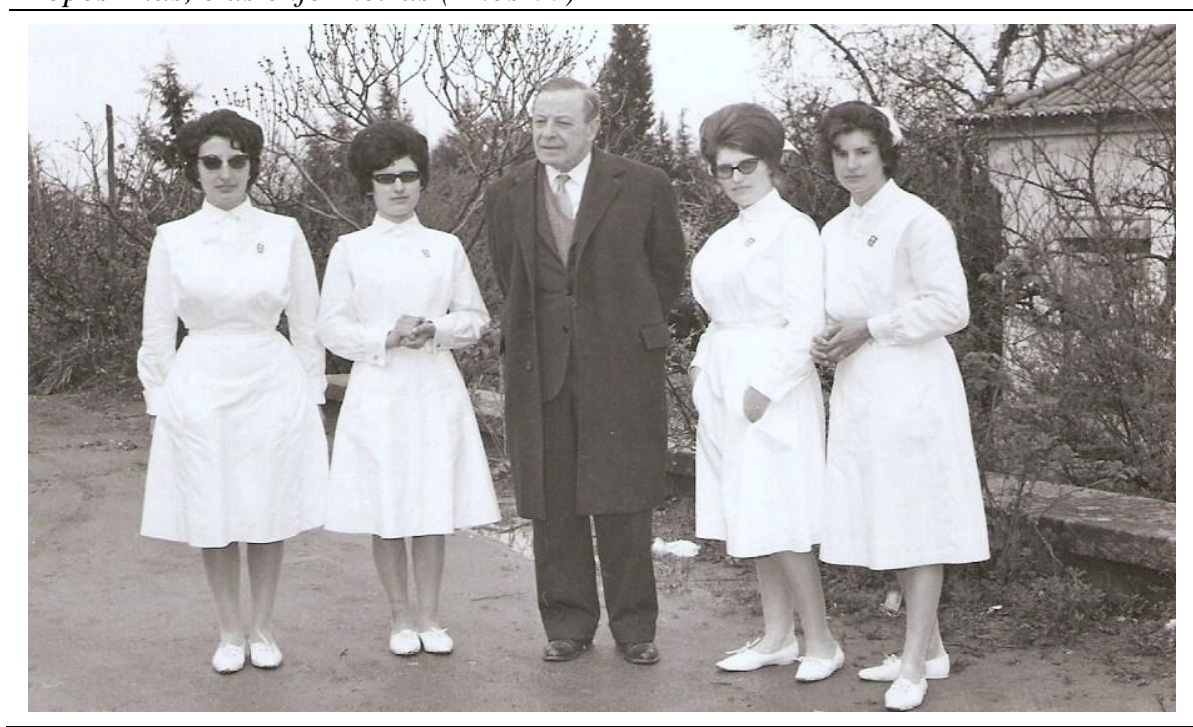

Outro aspeto que mereceu a intervenção do Estado, como já referimos atrás, prende-se com a preferência de elementos do género feminino para o ingresso nesta atividade. Procurava-se prolongar o domínio privado para o espaço público, tornando as mulheres enfermeiras submissas ao Estado e às atividades que conheciam e desenvolviam "naturalmente" em casa. A enfermeira representava um conjunto de valores e princípios associados a uma dimensão moral que o Estado promovia, por exemplo, num juramento que as enfermeiras deveriam de fazer no final do seu curso. Pode ler-se o seguinte:

“Perante V.Exª, representante legítimo da Autoridade, Juro, por Deus e pela minha honra:

- Que em tudo cumprirei as determinações da lei, da moral tradicional e dos regulamentos;

${ }^{27}$ Fonte: Imagem gentilmente cedida pela Enfermeira Maria Augusta Magalhães. 
- Que obedecerei ao médico pronta e fielmente dentro da minha profissão;

- Que não ultrapassarei os limites fixados pelo médico, e lhe darei contas rigorosas das iniciativas a que a urgência me obrigar;

- Que guardarei segredo acerca de tudo o que chegar ao meu conhecimento em razão do exercício da minha profissão;

- Que assistirei aos doentes com a maior caridade, delicadeza e dedicação;

- Que atenderei não só aos bens do corpo, mas também aos espirituais, familiares, profissionais e cívicos, seguindo o exemplo de S. João de Deus, nosso padroeiro;

- Que defenderei a sua vida até ao extremo, aproveitando todos os recursos da ciência e da técnica, e nada farei contra ela;

- E que respeitarei os cadáveres como sagrados despojos de irmãos

Este juramento constitui a base daquilo que a enfermeira podia ser e o que deveria representar para a sociedade da época. Dedicação, moral, abnegação, espiritualidade, bondade, entre outros, constituem os princípios norteadores do que significava ser enfermeira entre as décadas de 40 e 60 da centúria passada.

Outro exemplo interessante, prende-se com a proibição do casamento às enfermeiras hospitalares ${ }^{29}$. Para o Estado, a enfermagem deveria ser entendida como um sacerdócio e/ou uma missão, onde não cabia a família, devido às exigências daquele trabalho. Em 1963, depois de um longo debate sobre esta questão, que incluiu a própria Igreja na defesa do grupo, o Estado permitiu o casamento das enfermeiras $^{30}$.

Ser enfermeira entre os anos 40 e 60 era uma tarefa dura e, provavelmente, não constituía primeira opção para muitas das mulheres que se candidataram aos cursos, sobretudo de auxiliares de enfermagem. No entanto, estes cursos

${ }^{28}$ Arquivo da Escola de Enfermagem de Castelo Branco (AEECB) - Documentos avulsos - 1950 (sublinhado nosso).

${ }^{29}$ Sobre este assunto devem consultar-se os debates parlamentares (Debates Parlamentes Câmara dos Senhores Deputados, sessão de 25/03/1947, pp. 1044) e a campanha pelas enfermeiras portuguesas levadas a efeito pela Liga Portuguesa de Profilaxia Social.

${ }^{30}$ Decreto-lei no 44.923, de 06 de Março de 1963. 
possibilitavam o exercício de alguma autonomia, principalmente financeira, no contexto público e de serviço desinteressado ao outro.

A transição para a década de 60 trouxe uma lufada de ar fresco para a enfermagem. Aos poucos discutia-se quais os caminhos alternativos que podiam transformar a enfermagem em algo que nunca tinha sido, mas que podia vir a ser. $\mathrm{Na}$ sequência de alguns debates e da circulação de ideias em revistas da especialidade, o ensino e o exercício da enfermagem foram reformados em $1965^{31}$. Esta reforma constituiu uma viragem no que respeita à enfermagem em Portugal. Novos princípios estavam ali presentes. Princípios orientadores de uma enfermagem que se pretendia diferente num futuro próximo, capaz de afirmar uma jurisdição profissional própria, através da ciência, apesar da complexidade que representava Ser Enfermeira naquele tempo. A Este propósito refere-se o preâmbulo do decreto-lei da reforma de 1965:

“(...) a enfermagem é uma arte e uma ciência que, respeitando a dignidade do individuo, visa a promoção, manutenção e/ou aquisição de um estado de equilíbrio físico, mental e social, em conjunto com outras disciplinas de saúde e sociais. O enfermeiro como membro de uma equipa de saúde, planeia, executa e avalia cuidados de enfermagem que englobam a prestação de serviços aos indivíduos, como membro de uma família ou comunidade ${ }^{, 32}$.

Aos poucos a enfermagem encontrava caminhos próprios que poderiam ajudar à sua transformação em Saber aplicado ao individuo, à sociedade, utilizando para o efeito um conhecimento de fundo sobre os mesmos. As ciências sociais, humanas e comportamentais tiveram aqui um papel decisivo no processo de emergência e consolidação da enfermagem em Portugal.

Em suma, a segunda fase do processo de profissionalização da enfermagem portuguesa carateriza-se pela submissão a princípios impostos pelo Estado; pela política de género assumida e pela necessidade de um comportamento moral distinto. Por outro lado, a década de 60 constituiu o princípio da afirmação da enfermagem portuguesa que acabará por consolidar-se nos anos posteriores ${ }^{33^{3}}$.

\footnotetext{
${ }^{31}$ Decreto-Lei no 46.448, de 20 de Julho de 1965.

${ }^{32}$ Preâmbulo do Decreto-Lei no 46.448, de 20 de Julho de 1965.

${ }^{33}$ Constituição de carreira própria da enfermagem em 1967.
} 


\section{A ENFERMAGEM PORTUGUESA: O PROCESSO DE ENGRANDECI- MENTO (1970 - 1988)}

O final da década de 60 , da centúria passada, anunciava uma valorização crescente desta atividade. Em 1967, foram constituídas três carreiras próprias para a enfermagem: a de saúde pública, a hospitalar e a carreira do ensino.

"A carência de pessoal de enfermagem que actualmente se verificam impõem uma rápida actuação nos sectores, quer da saúde pública em geral, quer hospitalar, de modo a evitar o agravamento da situação presente e a permitir a realização dos programas existentes.

Torna-se, por isso, indispensável começar com a maior urgência, a intensificar as medidas que vêm sendo postas em prática, só por si insuficientes, de modo a conseguir, já no próximo ano lectivo, aumento significativo na frequência das escolas. Para tanto, estruturam-se as carreiras de enfermagem hospitalar, de saúde pública e de ensino (...)"34.

Como já evidenciamos noutros trabalhos "aquilo que parecia um avanço no processo de autonomia da enfermagem portuguesa foi, de facto, um elemento que dividiu, ainda mais, o grupo que prestava cuidados de enfermagem"35. O decretolei propunha várias carreiras de enfermagem com mecanismos e processos próprios para aceder às mesmas promovendo o sentido inverso ao desejado pelo grupo dos enfermeiros portugueses que era a coesão. O Estado manteve-se um elemento muito ativo no processo de construção identitária da enfermagem em Portugal.

Mesmo assim, no início da década de 70 a enfermagem portuguesa assumia já um protagonismo que nunca tinha conhecido. Foram reorganizadas as instituições escolares, a maioria dos/as docentes de enfermagem já eram enfermeiros/as, aprofundava-se o processo de cientificidade da enfermagem, por exemplo, com a organização do primeiro Congresso Nacional de Enfermagem $(1973)^{36}$. Neste

${ }^{34}$ Decreto-Lei $\mathrm{n}^{\circ}$ 48166, de 27 de Dezembro de 1967.

35 Henriques, H.M.G. (2012). Formação, Sociedade e Identidade Profissional dos Enfermeiros... cit., pp. $509-521$.

${ }^{36}$ O I Congresso Nacional de Enfermagem foi organizado pela Associação Católica dos Profissionais de Enfermagem e Saúde, pela Associação das Enfermeiras e dos Enfermeiros Portugueses e pela Federação Nacional dos Sindicatos Nacionais dos Profissionais de Enfermagem (composto pelos Sindicatos Nacionais de Lisboa, Porto, Coimbra e Funchal) e contou com o "alto patrocínio de Sua Excelência o Presidente da República, Almirante Américo de Deus Rodrigues Thomaz"36 revelando que o Estado mantinha-se atento àquilo que as/os enfermeiras/os discutiam sobre a importância da sua profissão, no contexto da época, assim como aos caminhos que desejavam tomar. 
evento apontaram-se os caminhos a seguir de modo a valorizar a atividade e a transformá-la definitivamente numa profissão. Salientamos, os três principais caminhos apontados: 1) o aprofundamento do Saber em enfermagem através das Ciências Sociais, Humanas e Comportamentais; 2) a necessidade de se instituir um código profissional; 3) a vantagem de integrar a enfermagem no ensino superior. A este respeito, Isaltina Goulart de Azevedo foi perentória:

“Aos vossos apelos, aos vossos governantes, para obtenção do nível superior para que se abram para vós as portas da Universidade Portuguesa, acrescentai, também um pedido desta modesta brasileira, que elevastes tão alto com a generosidade do vosso convite. E, se estes apelos puderem atingir as autoridades do vosso país, para a resposta que desejais, eu me sentirei recompensada de um vida de pelas, não menores do que as vossas pelos mesmos ideais, 37 .

A Comissão de Honra deste encontro contava com o Ministro dos Negócios Estrangeiros, o Ministro do Ultramar, o Ministro da Educação Nacional, o Ministro das Corporações e Previdência Social e da Saúde e Assistência, o Secretário de Estado do Trabalho e Previdência, o Secretário de Estado da Saúde e Assistência, o Secretário-geral do Ministério da Saúde e Assistência. Além destes elementos, também faziam parte o Diretor Geral de Saúde e Assistência do Ultramar, o Diretor Geral de Assistência Social, o Diretor Geral de Saúde e o Diretor Geral dos Hospitais. Juntavam-se a esta extensa lista de convidados de honra os inspetores técnicos de enfermagem de vários ministérios. Também as Misericórdias tinham lugar de honra, nomeadamente o Provedor da Misericórdia de Lisboa, assim como o seu inspetor de enfermagem. Além destes ainda se contavam com o Presidente do Conselho Nacional da Ação Católica Portuguesa, a Enfermeira Superintendente dos Serviços Médico-Sociais Universitários, a Presidente da Secção Hospitalar da Federação dos Institutos Religiosos Femininos e, naturalmente, os Presidentes dos Sindicato Nacionais dos Profissionais de Enfermagem do Distrito de Lisboa, do Distrito do Porto, do Distrito de Coimbra, do Distrito do Funchal e, também, o Presidente do Sindicato Nacional dos Profissionais de Enfermagem de Luanda.

A Comissão Organizadora era composta por três nomes relevantes no panorama da enfermagem portuguesa: a enfermeira Emília Maria Costa Cabral da Costa Macedo, Presidente da Associação Católica dos Profissionais de Enfermagem e Saúde; o enfermeiro Mário Sarmento Rebelo, Presidente da Federação Nacional dos Sindicatos Nacionais dos Profissionais de Enfermagem e a enfermeira Maria Teresa Basto Pereira Forjaz, Presidente da Associação das Enfermeiras e dos Enfermeiros Portugueses.

A coordenação geral dos trabalhos coube a Marta Hansen Lima Basto, que foi secretariada por Maria Helena Cadete Bernardo e cuja tesoureira foi Maria Carlota Sarmento Vasconcelos.

Além da Comissão Organizadora que apresentamos agora, existiam outras Comissões que se dedicavam a aspectos particulares como a organização das Comunicações Livres, a divulgação do congresso, a Comissão da Exposição, a Comissão de Fundos, a Comissão do Painel e Visitas de Estudo, a Comissão Sociocultural e a Comissão de Trabalho de Grupo.

Sobre este assunto deve consultar-se o capítulo V de HenRiQues, H.M.G. (2012), Op. Cit. pp. 520 e seguintes.

37 AzEVEDo, I. G. (1973). «O Papel do enfermeiro no mundo moderno». In Actas do $1^{o}$ Congresso Nacional de Enfermagem, ISU - Estabelecimentos de Saúde e Assistência. 
De acordo com a autora, só através da formação a enfermagem alcançaria a respeitabilidade académica, profissional e social desejada. Este caminho, passava pela integração no ensino superior como mecanismo legitimador da própria atividade. No mesmo sentido apontava Ismael Martins, professor e diretor da Escola de Enfermagem de Castelo Branco/Dr.Lopes Dias, quando se referia à importância destes congressos em entrevista realizada sobre o assunto em análise. O entrevistado salientava a importância da formação no contexto da enfermagem:

"A enfermagem torna-se um pouco difícil porque para ser bom enfermeiro, ou enfermeira, é preciso saber um pouco de tudo, não só um técnico prestador de cuidados como também é preciso ser psicólogo, sociólogo, filosofo e antropólogo e essas coisas todas o que não é possível. Não se pode ser bom nisto tudo, mas pode-se ter uns conhecimentos de base, para ajudar a conhecer melhor o ser humano, a entendê-lo e ajudá-lo, ${ }^{38}$.

Esta definição evidencia o carácter pluridisciplinar e transversal que a enfermagem assumia e a importância da formação académica e do conhecimento do Ser Humano como estratégia para destacar a jurisdição profissional da enfermagem junto da Sociedade.

O percurso ainda foi longo, não obstante alcançado em 1988 com a integração da enfermagem no ensino superior politécnico português ${ }^{39}$. Num despacho conjunto do Ministro da Saúde e do Secretário de Estado do Ensino Superior reconhecia-se formalmente a importância da atividade e do ensino da enfermagem. $\mathrm{O}$ legislador refere-se ao assunto do seguinte modo:

“- A educação em enfermagem é de nível superior e deverá garantir o equilíbrio entre a competência académica e cientifica e a competência técnica e profissional.

- A educação em enfermagem será da dupla tutela do Ministério da Educação e do Ministério da Saúde, de acordo com as condições que superiormente venham a ser definidas na sequência do protocolo de colaboração genérica a celebrar entre os dois Ministérios.

- A autonomia da enfermagem terá de ser salvaguardada pelo que a orientação e a responsabilidade da educação em enfermagem deverão continuar a pertencer a enfermeiros da carreira docente respectiva.

${ }^{38}$ Cf. Entrevista realizada ao Enfermeiro Ismael Martins, pp. 22 (HENRIQUES, H. M. G. (2012), Formação, Sociedade e Identidade Profissional dos Enfermeiros..., cit, Cd com anexos).

${ }^{39}$ Decreto-Lei n ${ }^{\circ} 480$, de 23 de Dezembro de 1988. 
- Deverá continuar a haver um só nível de formação de base em enfermagem pelo que o actual curso de enfermagem geral será substituído pelo curso superior de enfermagem que conferirá o grau académico de bacharel.

(...) - As habilitações literárias de acesso à formação de base em enfermagem deverão ser do nível exigido para o ensino superior em geral. $(\ldots)^{, 40}$.

Este momento constituiu, em nosso entender, o ponto de viragem em relação a entendimentos anteriores sobre a atividade. Assim, permitiu que em 1996 a enfermagem alcançasse outro objetivo de importância capital: a criação do Regulamento do Exercício Profissional dos Enfermeiros (REPE) ${ }^{41}$. Pouco tempo depois, seria criada a Ordem dos Enfermeiros portugueses (1998) ${ }^{42}$. Este conjunto de elementos tornaram a enfermagem uma atividade profissional relacional com autonomia face a outros grupos e promoveram um conjunto de relações com vários saberes, nomeadamente a psicologia, sociologia e pedagogia, que permitiram constituir uma jurisdição académica e profissional própria a que chamaram de cuidados de enfermagem.

\section{CONSIDERAÇÕES FINAIS}

A história das profissões é um domínio que apresenta um conjunto vasto de potencialidades teóricas e empíricas. No caso da enfermagem portuguesa, observamos que ao longo da centúria de novecentos o seu desenvolvimento caraterizou-se por avanços e recuos. Consideramos, no entanto, que o desenvolvimento de uma ideologia profissional encontra-se ancorada à criação de escolas de enfermagem e ao seu papel ao nível do recrutamento, da relação com o Estado e de acordo com as logicas formativas. Como dissemos, foi no último quartel do século XIX que surgiram as primeiras instituições escolares que tinham como objetivo formar enfermeiros em Portugal. Estas instituições favoreceram a constituição de estratégias e a criação de uma consciência de grupo que promoveu a transformação da enfermagem de ocupação para uma profissão relacional.

Este processo encontra-se ligado ao papel dinâmico que o Estado assumiu na construção identitária deste grupo. Por um lado, possibilitou o afastamento da enfermagem em relação às administrações hospitalares, numa primeira fase,

40 AEECB - Oficio enviado à Escola de Enfermagem de Castelo Branco - Integração do ensino da enfermagem no sistema educativo nacional, 16 de Janeiro de 1985.

${ }^{41}$ Decreto-Lei n ${ }^{\circ}$ 161, de 04 de Setembro de 1996.

${ }^{42}$ Decreto-lei $n^{\circ}$ 104, de 21 de Abril de 1998. 
todavia submeteu a enfermagem a uma moral profissional caraterizada pela submissão ao grupo profissional dos médicos e ao Estado. No mesmo sentido, alocou a mulher solteira ao exercício da enfermagem, impedindo-a de casar durante algumas décadas, possibilitando-lhe a entrada no mercado de trabalho. Não obstante, esta vocação feminina não passou de um mecanismo de controlo do público feminino na esfera pública observando-se um prolongamento dos cuidados domésticos para o tecido social, com regalias mínimas. A década de 40 constituiu um importante marco temporal para o desenvolvimento da enfermagem enquanto atividade "auxiliar da medicina". Esta mesma década a enfermagem iniciou um processo de acreditação que colocaria a enfermagem num patamar legal onde nunca estivera anteriormente. Para ser enfermeira era preciso um diploma escolar.

A "libertação" da enfermagem aconteceu a partir da década de 60, nomeadamente depois da reforma de 1965, quando os enfermeiros consolidaram gradualmente um processo de apropriação das escolas de enfermagem. O controlo das instituições escolares, permitiu selecionar os saberes necessários ao desenvolvimento da atividade. Neste contexto, as ciências sociais, humanas e comportamentais passaram a ter uma centralidade enorme, uma vez que permitiam a aquisição de novas técnicas e métodos de trabalho de que a enfermagem se ia apropriando. Esta apropriação permitiu aos poucos valorizar o conhecimento produzido pelos enfermeiros, organizar grandes eventos científicos, apostar numa formação onde o Ser Humano era na sua globalidade o principal foco, ao contrário do que acontecia anteriormente com a conceção bio-médica da enfermagem. Deste modo o grupo foi desenvolvendo saberes e saberes-fazer que possibilitaram a aquisição de maior dignidade profissional, académica e social e, ainda, a constituição de um domínio profissional próprio a que chamam de "cuidados de enfermagem". Este foi um processo complexo, mas que permitiu a integração da enfermagem no ensino superior, a aquisição de um regulamento profissional e a constituição da Ordem dos Enfermeiros em Portugal colocando a enfermagem no mesmo nível de outros grupos relacionados com a saúde. 
